$$
\begin{aligned}
& \text { CONF-961202- }-34 \\
& \text { ANL/MSD/CP- - } 91861
\end{aligned}
$$

\title{
PLASTIC FLOW INDUCED BY SINGLE ION IMPACTS ON GOLD*
}

R. C. Birtcher and S. E. Donnellya

- $F I V E D$

IAN 161997

$\cup \mathrm{STI}$
Materials Science Division Argonne National Laboratory

Argonne, IL 60439

aJoule Physics Laboratory Science Research Institute University of Salford M5 4WT United Kingdom

December 1996

The suomitted manuscript has
been created by the University of
Chicago as Operator of Argonne
National Laboratory ("Argonne")
under Contract No. W-31-109-
ENG-38 with the U.S. Department
of Energy. The U.S. Government
retains for itself, and others
acting on its behalf, a paid-up,
non exclusive, irrevocable
worldwide license in said article
to reproduce, prepare derivative
works, distribute copies to the
public, and perform publicly and
display publicly, by or on behalf
of the Government.

Presented at the Materials Research Society, December 2-6, 1996, Boston, MA.

*Work supported by the U. S. Department of Energy, Office of Basic Energy Sciences, under Contract W-31-109-Eng-38 at Argonne National Laboratory. 


\section{DISCLAIMER}

Portions of this document may be illegible in electronic image products. Images are produced from the best available original document. 
R. C. Birtcher ${ }^{1}$ and S. E. Donnelly 2

1 Materials Science Division, Argonne National Laboratory, Argonne, IL. 60439

2 Joule Physics Laboratory, Science Research Institute University of Salford M5 4WT, UK

\section{ABSTRACT}

In situ transmission electron microscopy has been used to follow room temperature irradiation of thinned bulk and $62 \mathrm{~nm}$ thick gold films with $\mathrm{Xe}$ ions in the energy range 50 to $400 \mathrm{keV}$. Energy spikes resulting from single ion impacts give rise to surface craters and holes which exist until annihilation by subsequent ion impacts. Video recording provided details with a time-resolution of 33 milliseconds. Craters were produced on the irradiated surface at all ion energies and on the opposite surface when the ions had sufficient energy to traverse the specimen. Crater sizes were as large as $12 \mathrm{~nm}$ for the higher energy irradiations. On average, approximately $6 \%$ of impinging ions result in craters.

A single $200 \mathrm{keV} \mathrm{Xe}$ ion may produce a hole in thin gold foils. Hole formation involves the movement by plastic flow of massive amounts of material; on the order of tens of thousand $\mathrm{Au}$ atoms per ion impact. Individual ion impacts also result in a filling of both holes and craters as well as a thickening of the gold foil. Change in morphology during irradiation is attributed to a localized, thermal-spike induced melting, coupled with plastic flow under the influence of surface forces.

\section{EXPERIMENTAL}

In situ ion irradiations were carried out in a Hitachi A-9000 TEM operating at $300 \mathrm{keV}$ at the IVEM/Accelerator Facility located at Argonne National Laboratory [1]. The ion beam is oriented $30^{\circ}$ from the microscope axis, and the specimen was tilted $15^{\circ}$ towards the ion beam so that both ions and electrons were incident on the specimen at $15^{\circ}$ to the foil normal. Specimens were irradiated with $\mathrm{Xe}$ ions at energies of $50 \mathrm{keV}$, $200 \mathrm{keV}$ or $400 \mathrm{keV}$ at dose rates between 1 and $2510^{10} \mathrm{ions} / \mathrm{cm}^{2} / \mathrm{s}$.

Thin Au films, $62 \pm 5 \mathrm{~nm}$ with a $<100>$ surface normal, were made by evaporation of 99.999 at \% pure starting material onto $\mathrm{NaCl}$ at a temperature of $350^{\circ} \mathrm{C}$. Small pieces of $\mathrm{Au}$ were floated off on a water/alcohol mixture and picked up on either $\mathrm{Au}$ or $\mathrm{Cu}$ TEM grids. Bulk TEM specimens were prepared by jet-polishing [2], 99.999 at. \% pure Au with grain size greater than $10 \mu \mathrm{m}$ having a (110) texture.

Surface features were made visible in the TEM by defocusing the objective lens of the microscope (typically $\approx 1000 \mathrm{~nm}$ of underfocus). Photographic recording were made during interruptions of the irradiations, and images from a Gatan 622 video camera and image- 
intensification system were continuously recorded during irradiation on video tape with a time resolution of $1 / 30$ th second (a single video frame). The temporal resolution is clearly insufficient to yield information on the ballistic phase of the collision cascade which persists for picoseconds or less. However, the system clearly identifies the plastic flow processes associated with individual impacts.

\section{RESULTS}

Figure 1 shows images digitized from video recordings made during the continuous $\mathrm{Xe}$ ion irradiation. Figure $1 \mathrm{~A}$, recorded during a $50 \mathrm{keV} \mathrm{Xe}$ irradiation, shows a small crater observed for irradiations at all energies studied. Figure 1B was recorded during a $200 \mathrm{keV} X \mathrm{Xe}$ irradiation and shows a larger faceted crater and pre-existing small craters. The craters in figures $1 \mathrm{C}$ through $1 \mathrm{E}$ were produced by $400 \mathrm{keV} \mathrm{Xe}$ ions. In each case, material is deposited on the surface concomitantly with crater formation. In figure 1C, a faceted crater is surrounded by a faceted island. In figure 1D, a two-part "lid" appears to have been ejected from the crater. Such

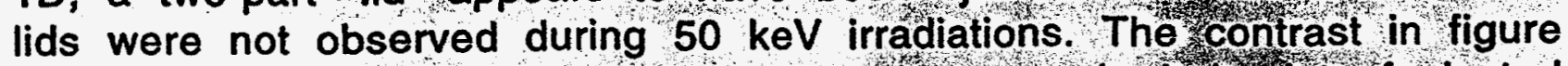
$1 E$ is consistent with a faceted crater and a quenched droplet of ejected molten material. (The light contrast to the right of $\mathrm{Whis}$ crater is the

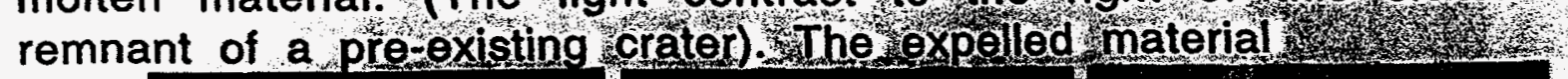
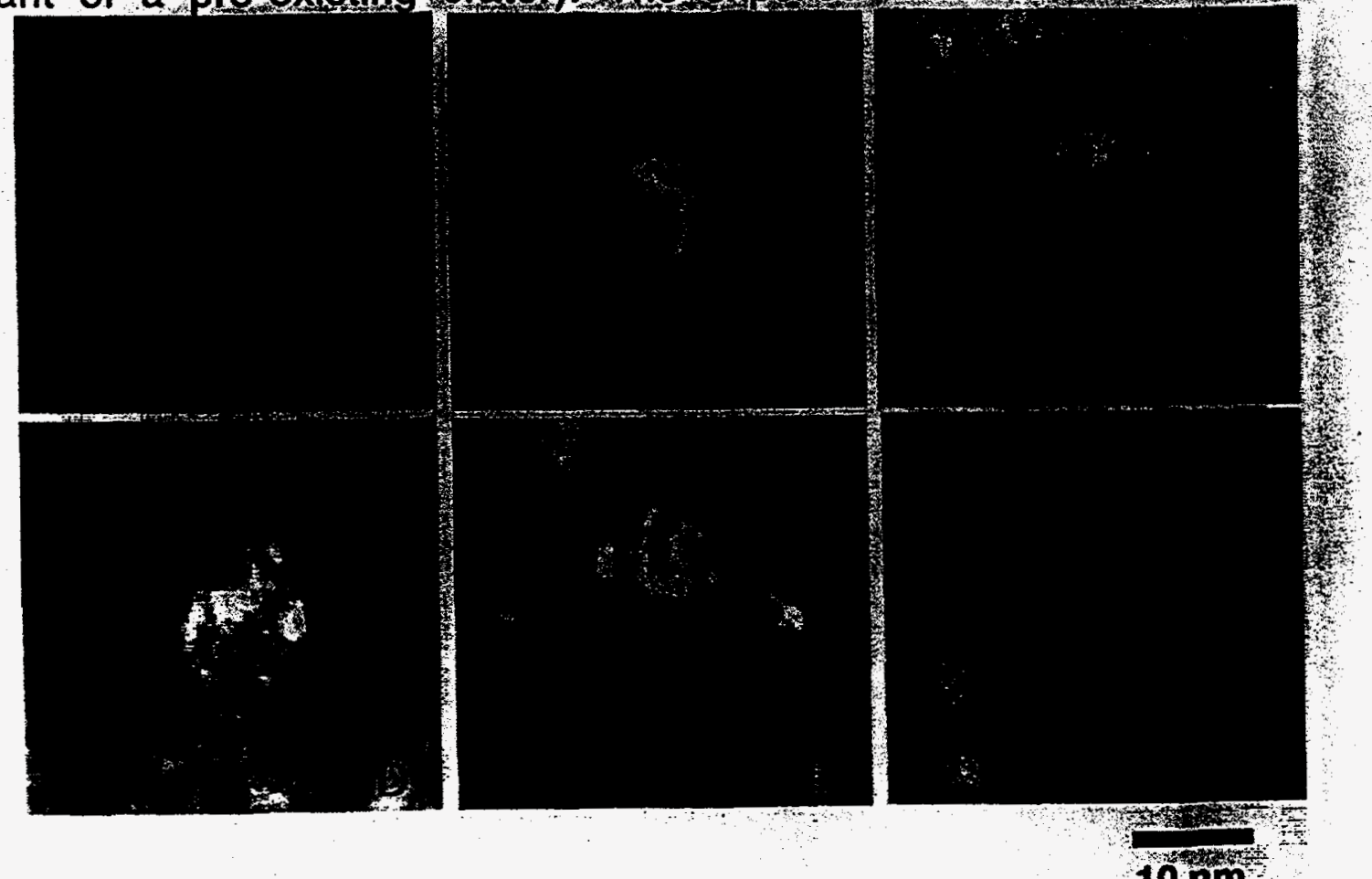

Figure 1: Images digitized from video recordings resulting from single $X e$ ion impacts at A) $50 \mathrm{keV}$, B) $200 \mathrm{keV}$ and C), D) and E) $400 \mathrm{keV} \mathrm{Xe} \mathrm{ions.} \mathrm{f)}$ an isolated particle which appeared on the surface (between video frames) during irradiation with $400 \mathrm{keV}$ Xe ions. 
contains approximately 20,000 gold atoms. The largest craters involved as many as 40,000 gold atoms. Figure $1 F$ shows a particle on the surface that has appeared between successive video frames with no associated crater within a field of view approximately six times the area shown. Craters were also found by Merkle and Jäger after $\mathrm{Bi}$ ion irradiation of $\mathrm{Au}$ at room temperature [3].

Analysis of more than 200 craters recorded on videotape reveals that the mean crater area increases from $14 \mathrm{~nm}^{2}$ at $50 \mathrm{keV}$ to $32 \mathrm{~nm}^{2}$ at $200 \mathrm{keV}$ and $34 \mathrm{~nm} 2$ at $400 \mathrm{keV}$. For the small number of craters studied using stereoscopic techniques, both small and large craters appeared on both surfaces during $200 \mathrm{keV}$ and $400 \mathrm{keV}$ irradiations of $62 \mathrm{~nm}$ thick films. The number of craters imaged in this manner, however, was insufficient to draw conclusions concerning differences in size distribution for the two surfaces.

The images recorded on videotape during continuous irradiation reveals a rapidly changing crater population with crater creation and annihilation [4]. If the irradiation is interrupted, both creation and annihilation cease. At any time approximately 7 craters were in the field of view $(110 \mathrm{~nm} \times 85 \mathrm{~nm})$. At the dose rate used in the experiment, 2.4 1011 ions $/ \mathrm{cm}^{2} / \mathrm{s}$, statistically, there is one ion impact per second on the area of each segment of figure 1. The efficiency of crater creation is on the order of $6 \%$ (ranging from $2 \%$ to $10 \%$ ) implying that the majority of ion impacts annihilate craters without creating new ones.

Under steady-state conditions of continual irradiation, at a dose rate of $2.410^{11}$ ions $/ \mathrm{cm}^{2} / \mathrm{s}$, craters have a lifetime in the range $1-12 \mathrm{~s}$ at all ion energies studied. Small craters are generally annihilated in a single discrete event whereas larger craters disappear in two or more steps. Each event occurred within the time of 1 video frame capture or $1 / 30 \mathrm{sec}$ and was produced by a single ion. Lifetime measurements on 14 craters with a mean diameter of 4.4 . $\mathrm{nm}$ yield a mean lifetime of $4.9 \mathrm{~s}$ for craters annihilated in a single step. With the assumption that all ion impacts are capable of annihilating existing craters, the $\mathrm{Xe}$ ion has an annihilation cross section for small craters of approximately $85 \mathrm{~nm}^{2}$, i.e. an ion impact within a radius of approximately $5 \mathrm{~nm}$ of the center of a small crater will annihilate the crater.

The use of carbon collector foils shows that crater formation is not, in general, accompanied by the emission of crater-sized particles although occasionally such a particle is emitted from the surface. A crude estimate of the probability of cluster emission by a $400 \mathrm{keV}$ ion is $\approx 3$ 10-5 particles/ion corresponding to approximately one particles per 2,500 craters [4].

In the thinnest areas of bulk foil many single ion impacts resulted in the creation of holes [5] having diameters between 5 and $10 \mathrm{~nm}$ as shown in figure 2. Approximately $1 / 2 \%$ of the $\mathrm{Xe}$ ions produced holes. 
Measurements the area shown in fig. 2. made with a $50 \mathrm{~nm}$ diameter electror beam. ndicate that no holes were creates in regions with thickness greate: than about $50 \mathrm{~nm}$. On the order of $1{ }^{\circ} \circ 0$ of all ions stop in the last $2 \mathrm{~nm}$ of a $50 \mathrm{~nm}$ thick specimen. This suggests that it is only when ion damage extends through the entire specimen thickness that a hole may be formed.

Figure 2-(3) shows a hole (B) appearing next to a previously created hole (A) (The number under each section of the figure refers to the videoframe from which the image was taken, with the first frame of the figure being numbered 1. The contrast within the holes is due to noise in the imaging system.). The shape of the hole is recorded, by the nature of the image recording, long after the cascade that produced it has ended and as such includes any annealing that occurs during the cascade quenching. Note that we also observe formation of craters on one or the other surface [5]. An ion strikes the entire area shown in figure 2 on average every 10

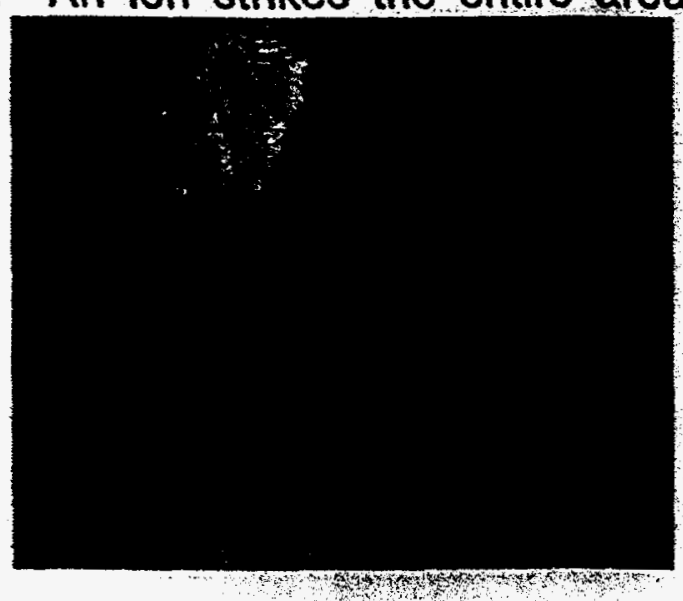

FRAME 1

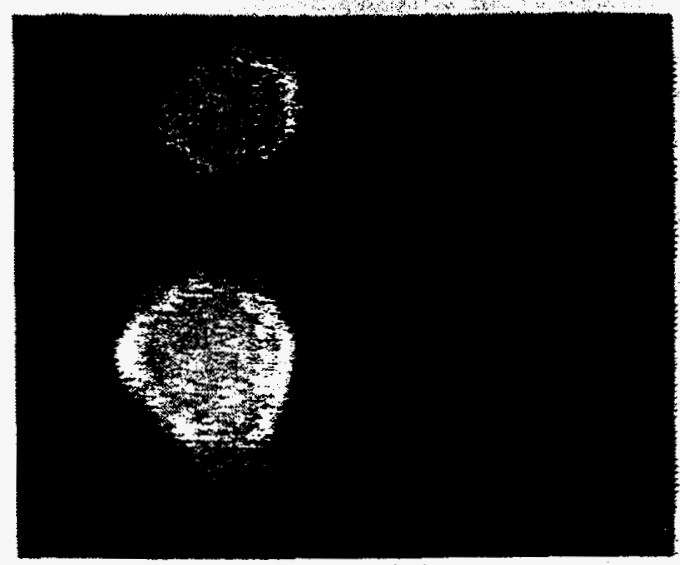

FRAME 79

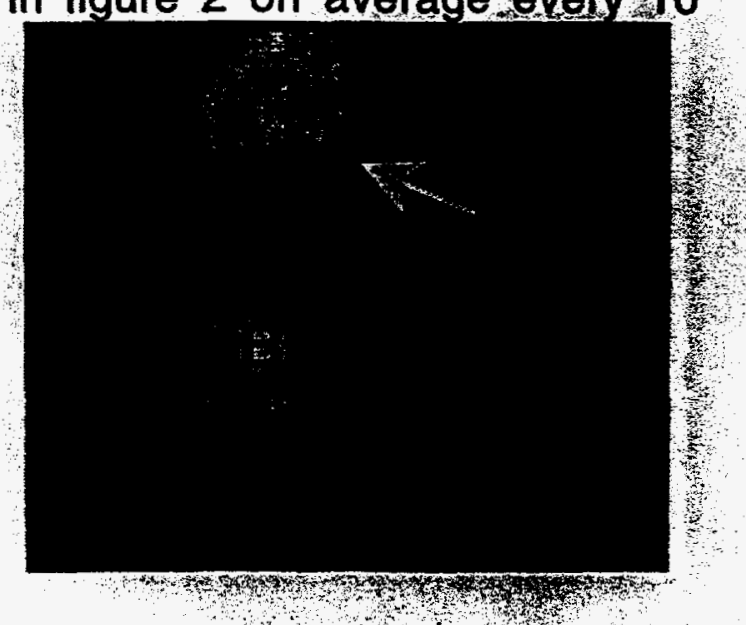

FRAME 3

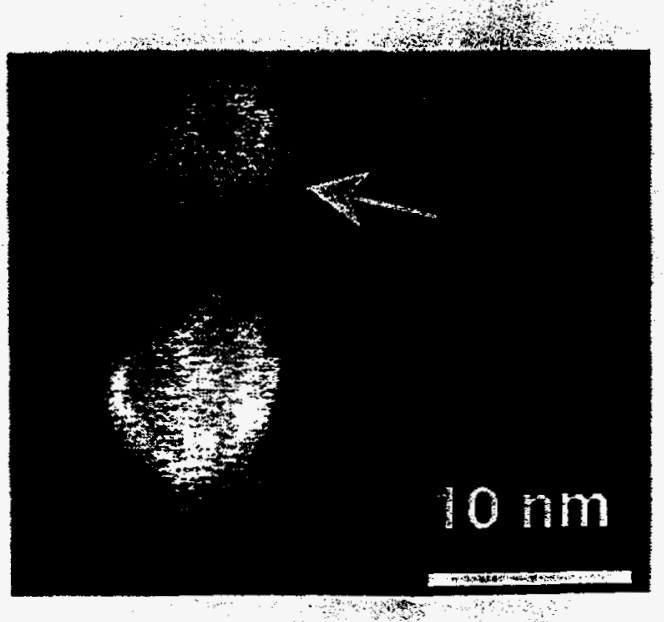

FRAME 80

Figure 3 Discrete structural changes of a Au foil during $200 \mathrm{keV} \mathrm{Xe}$ irradiation at room temperature. (The numbers under each part of the figure refer to the video-frame from which the image was taken, with the 
first frame of the figure being numbered (1). The frames were recorded at 30 per second)

frames or $0.3 \mathrm{~s}$ which is much longer than the cascade lifetime of a few tens of picoseconds. The holes in figure 2 appear between successive video frames (within a time period of 1/30th second) and have been made by single ion impacts. Assuming a foil thickness between 20 to $50 \mathrm{~nm}$, between 20,000 to 50,000 gold atoms were removed to create hole (B). This would imply in an enormously high sputtering yield if the atoms were ejected from the gold surface. However, the change in image contrast suggest that these atoms have been moved to the specimen surface. Although expelled material is likely to be closely associated with a hole occasionally small particles appear far from any hole or crater. This is consistent with STM images that show adatom islands on ion irradiated $\mathrm{Pt}$ surfaces [6].

A second equally striking observation is the change in the shape and size of holes during continued irradiation as also shown in figure 2. Although holes have been annealed by the quench phase of their own cascade, additional ion impacts may produce further annealing. These changes occur in both large steps, such as when hole $B$ is formed, and small steps as illustrated between figures $2-(3)$ and 2-(15). The partial filling of hole $A$ resulted from plastic flow of material away from the site of hole (B) as indicated by the arrow on fig 2-(3). No further major changes are observed until frame 80 when an ion impact causes an enlargement of hole $B$, and material from the impact partially fills hole $A$ in the region indicated by the arrow on figure 2-(80). In general, filling of holes does not depend on a second hole being near, and frequently the impact event responsible for a change does not itself produce a visible feature. Although not shown, when the ion irradiation is stopped flow of material ceases and there is no further change to the morphology of the gold foil.

Many ion impact events change the shape of existing holes. Rounding of holes in figure 2 is a persistent process that takes place in discrete events. Changes in hole shape are generally due to cascade events that do not produce new holes but generate plastic flow near to existing ones. Although an energetic ion impact may initially give rise to an explosive outflow of material, during the quenching phase of the molten zone to the solid state, surface tension forces will act on any free surfaces involved with the melt zone. This gives rise to changes in the shape of edges and the tendency of holes to become more circular.

It has been a long-standing observation in our laboratories that thin areas of irradiated gold specimens disappear [3]. This is a consequence of plastic flow during heavy-ion irradiation even if holes do not form. Our insitu observations [5] reveal that the thickening occurs in pulses as a result of ion-beam induced plastic flow. When observed at a high doserate this process appears to be similar to changes that occur when thin 
gold foils are heated to close to the bulk melting temperature and surface tension forces cause the material to flow. Frame-by-frame analysis, however, shows this process to be a pulsed localized flow identical to that responsible for the rounding of holes. As in the case of hole production, only a small fraction of ion impacts result in major changes.

\section{SUMMARY}

In situ observations demonstrate that impacts of individual xenon ion in the energy range of 50 to $400 \mathrm{keV}$ continuously create and annihilate craters on the surface of gold during room temperature irradiation. These structures are stable at room temperature when irradiation ceases. The efficiency of crater production is $\approx 0.06$ craters per ion and the cross section for crater annihilation is approximately 85 $\mathrm{nm}^{2}$. Crater formation is not, in general, accompanied by the emission of crater-sized particles although occasionally $(\approx 1$ per 10000 craters $)$ such a particle is emitted from the surface. Crater creation and annihilation result from radiation-induced flow and surface diffusion driven by cascade energy spikes.

In the thinnest areas of the bulk foils single ion impacts resulted in the creation of holes with diameters between 5 and $10 \mathrm{~nm}$. Approximately $1 / 2 \%$ of the $\mathrm{Xe}$ ions produced holes. Holes result from only a small percentage of ion impacts with other impacts cause cratering while the majority of ion impacts result in plastic-flow annealing of features, holes, craters and specimen edge, having small radii of curvature.

lon-induced, pulsed localized plastic flow is a fundamental process that changes the morphology of an irradiated gold foil. It is likely to occur in other high- $Z$ materials where displacement cascades are strongly localized such that molten zones form. We believe that plastic flow may also be responsible for other processes occurring in gold under ion irradiation such as ion-induced bubble motion observed during $\mathrm{Xe}$ irradiation of $\mathrm{Au}$ containing $\mathrm{He}$ bubbles [7] and grain-boundary movement [8].

\section{ACKNOWLEDGMENT}

Work supported by the US department of Energy, Office of Basic Energy Science, under Contract W-31-109-Eng-38 at Argonne National Laboratory.

REFERENCES

1. C. W. Allen, L. L. Funk, E. A. Ryan and S. T. Ockers, Nucl. Inst. and Meth. B $\underline{40 / 41}, 553$ (1989).

2. B. J. Kestel, Ultramicroscopy 25, 351 (1988).

3. K. L. Merkle and W. Jager, Phil. Mag. A 44, 741 (1981).

4. S. E. Donnelly and R. C. Birtcher, submitted to Phys. Rev. B 1996.

5. R. C. Birtcher and S. E. Donnelly, Phys. Rev. Lett 77, 4374, 1996

6. C. Teichert, M. Hohage, T. Michely and G. Comsa, Phys. Rev. Lett. $\underline{72,} 1682$ (1994).

7. S. E. Donnelly, R. C. Birtcher and C. Templier, Phys. Rev. B 52, 3970 (1995).

8. R. Kelly, Rad. Eff. 32, 91 (1977). 